\title{
Vascularization of vessel pedicle in hypospadias and its relationship to near-period complications
}

\author{
ZHANG ZHAO ${ }^{1,2^{*}}$, NING SUN $^{3 *}$ and XIANGMING MAO ${ }^{1,4}$ \\ ${ }^{1}$ Department of Urology, Southern Medical University, Guangzhou, Guangdong 510515; ${ }^{2}$ Department of \\ Urology, Guangzhou Women and Children's Medical Center, Guangzhou, Guangdong 510623; ${ }^{3}$ Department of \\ Urology, Beijing Children's Hospital, Beijing 100045; ' Department of Urology, Zhujiang Hospital, \\ Guangzhou, Guangdong 510000, P.R. China
}

Received November 28, 2017; Accepted May 8, 2018

DOI: $10.3892 /$ etm.2018.6475

\begin{abstract}
The present study evaluated the relationship between the vascularization of vessel pedicle and the near-period complication by assessing the surgery effect and recognizing the blood supply of the material for urethra reconstruction and collected the follow-up of the hypospadias patients after the operation. We illuminated the prepuce by a lighting technique using cold light and then photographed, and recorded the distribution and the quantity of vessels. Then classified, analyzed and summarized the vascularization of vessel pedicle. Patients who were repaired by Duckett technique were followed up for 1-5 months after the operation. We classified vessel pedicle vascularization in hypospadias cases into four patterns based on the predominant blood vessels. The number of predominant vessels had no exact relationship to the meatal location. The incidence of fistula and stricture had no exact relationship to the number of predominant vessels. In conclusion, there is no exact congruent relationship between the types of vascularization with the meatal location. Vascularization of vessel pedicle had no exact relationship with urethral fistula or stricture.
\end{abstract}

\section{Introduction}

Hypospadias is a condition where the urethra opens on the underside of the penis with associated ventral penile curvature, and it is the second most common genital birth defect in boys, following cryptorchidism. The incidence of hypospadias is 1:200-1:300 male births, and has doubled over the past three decades. Hypospadias correction is one of the common

Correspondence to: Dr Xiangming Mao, Department of Urology, Southern Medical University, 1838 North Avenue, Guangzhou, Guangdong 510515, P.R. China

E-mail: michael_zhao1986@163.com

*Contributed equally

Key words: hypospadias, prepuce, vascular distribution, postoperative complications surgical procedures performed by pediatric urologists $(1,2)$. The initial diagnosis of hypospadias is typically made during physical exam after birth, where boys with hypospadias are found to have a ventral skin deficiency with a dorsal hood of foreskin and an abnormally located meatus with varying degrees of ventral penile curvature. The standard classification of hypospadias is based on the location of the urethral meatus: distal, midshaft, or proximal. For operative planning, many aspects of the hypospadias information are taken into consideration: location of the meatus and the degree of proximal spongiosal hypoplasia; quality of the urethral plate; size of the glans and the depth of the navicular fossa; degree of ventral skin deficiency and availability of the foreskin, and so on. The most common early complications of hypospadias surgery include urethral fistula, stricture and diverticulum dilatation (3). Both the occurrences of urethral fistula urethral stricture are related to the blood supply of molding material for urethra reconstruction (4).

There are quite detailed research on blood supply of normal penis, and the recognition towards prepuce vascular distribution is relatively consistent (5). But quite limited research has been done in prepuce vascular distribution in children with hypospadias, especially in the Chinese. A correct recognition of prepuce vascular distribution in child cases with hypospadias is very important to understand the blood supply of molding urethra, operative prognosis and surgical operation.

In this report, the authors generalized, analyzed and summarized vascular distribution of vessel pedicle in children with hypospadias through transmitting prepuce with cold light illuminator, and carried out a prospective study to discuss the blood supply of different vascular distribution types as well as their relevance to short-term complications after operation.

\section{Patients and methods}

Patients. Our study received approval of the Ethics Committee of Guangzhou Women and Children's Medical Center (Guangzhou, China) Affiliated to Capital Medical University (Beijing, China), and informed consent was signed by the parents of the patients. This study was conducted on primary cases with subcoronal, distal- or mid-penile hypospadias and suitable for urethroplasty. Cases with glanular, recurrent, or 

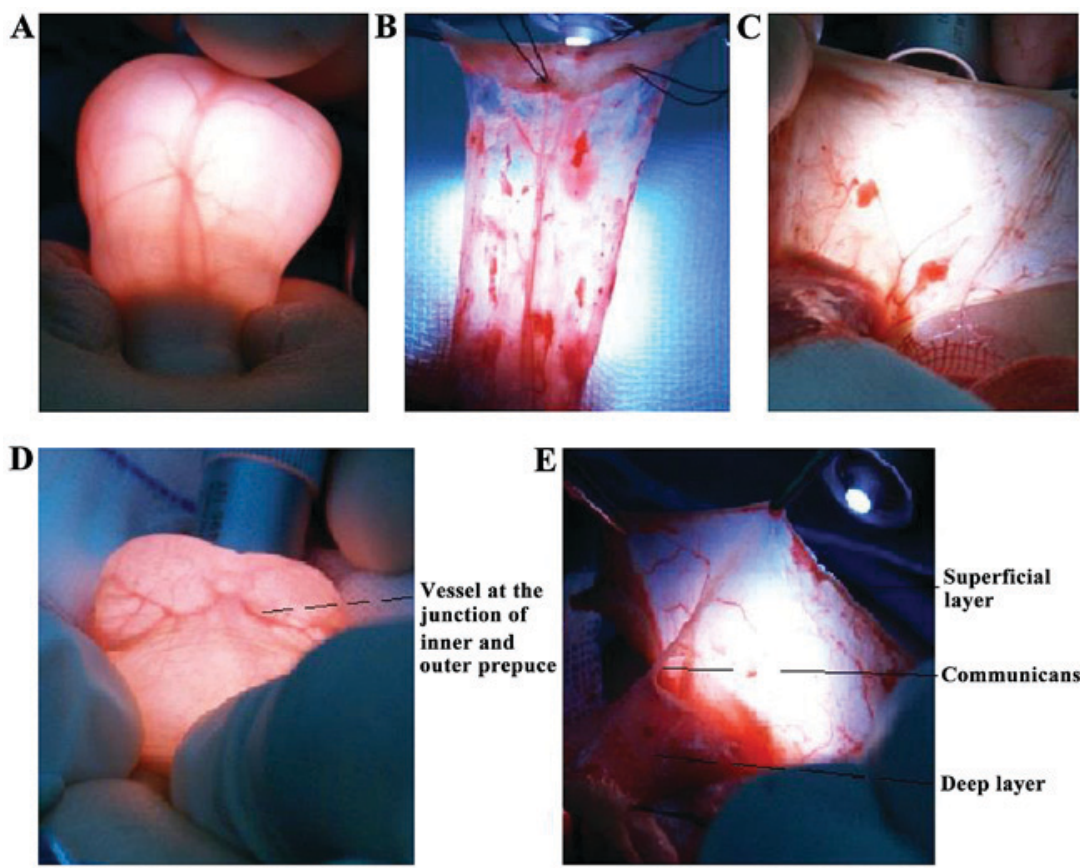

Figure 1. Trans-illumination with endoscopic cold light source. (A) The overall vascular distribution of prepuce; the vascular distribution of (B) vascular pedicle of flap and (C) skin; (D) blood vessels at the junction of inner and outer prepuce; (E) ramus communicans.

moderate-to-severe chordee were excluded from the study. A total of 115 children with hypospadias undergoing surgery at Beijing Children's Hospital affiliated to Capital Medical University (Beijing, China), between October 20, 2010 and March 2, 2011 were selected as the research objects (age range, 1-12 years; median age, 24 months; mean weight, $11.35 \mathrm{~kg}$; mean height, $87.20 \mathrm{~cm}$ ). The surgeon was a pediatric urology surgery specialist trained for $>10$ years with $>15$ years of experience in hypospadias repair surgery. The surgical methods included Duckett, ONLAY, Snograss, and MAGPI (meatal advancement and glanuloplasty). Pedicled flaps of prepuce were cut for urethral molding in Duckett and ONLAY (onlay island flap); peeled vascular pedicle were to cover the new urethra in Snodgrass and MAGPI (6).

Methods. Endoscopic cold light source was used to trans-illuminate the prepuce (before the operation), flap vascular pedicle and residual prepuce skin (during the operation) (Fig. 1). All data were saved in the form of photographs, and the distribution and number of blood vessels were observed by two observers, then recorded and analyzed. Child patients undergoing Duckett procedure were followed up for 1-5 months to understand the occurrence of complications considering that the flap used in molding urethra by Duckett mostly depends on the blood supply from pedicle blood vessels.

Statistical analysis. Data were analyzed by SPSS 19.0 software (IBM Corp., Armonk, NY, USA). Data were analyzed using the Chi-square test, and differences between groups were considered significant at $\mathrm{P}<0.05$.

\section{Results}

Vascular distribution within the vessel pedicle. The number and distribution of superficial vessels within the prepuce varied, and there was no clear relationship between the superficial and deep vessels of the prepuce. In terms of the overall prepuce, the superficial vessels and deep vessels were easily distinguishable (Fig. 1A); however, the deep vessels were usually on or leaned towards the middle line (Fig. 1A). These blood vessels were later horizontally distributed at the junction of the inner and outer prepuce (Fig. 1D). The deep layer of the superficial fascia together with the skin at the junction of the inner and outer prepuce constituted a peduncle island skin flap, and the superficial layer of the superficial fascia supplied blood to the remaining skin (Fig. 1B). Occasionally, a ramus communicans was visible between the superficial and deep layers of the superficial fascia or between the superficial fascia and deep fascia (Fig. 1E).

The vascular distribution and length of the vascular pedicle (deep layer of the superficial fascia) were obviously regular. When based on the number of predominant blood vessels, the following four types of vascular pedicles were identified: i) one blood vessel was predominant (Fig. 2A); ii) two blood vessels were predominant (Fig. 2B); iii) numerous blood vessels ( $\geq 3$ ) were presented (Figs. 2C and D); and iv) no predominant blood vessel was presented (e.g., no definite axial vessel displayed a network distribution) (Fig. 2E). All types of predominant vessels were axially distributed, and then showed a transverse distribution and formed numerous reticular lateral branches at the junction of the inner and outer prepuce. The predominant vessels in the same pedicle displayed no obvious difference in their development, and a majority was symmetrically distributed along the middle line of the pedicle. The patients were assigned to four different groups based on their meatal location (Table I). Next, the Chi-square test showed that the number of predominant vessels was not directly related to the meatal location $(\mathrm{P}=0.449)$.

Follow-up. Eighty-three children were treated with Duckett procedure. Seventy-nine of the children received follow-up and 

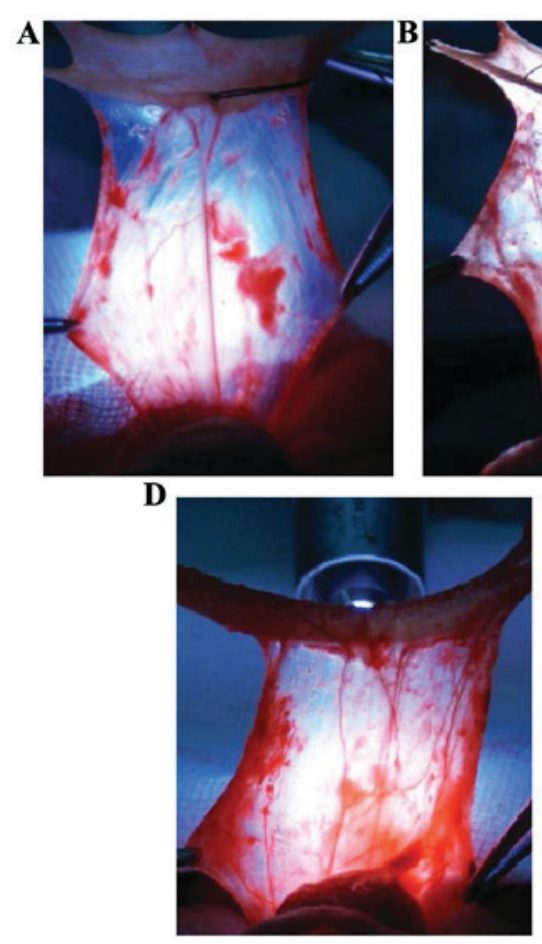
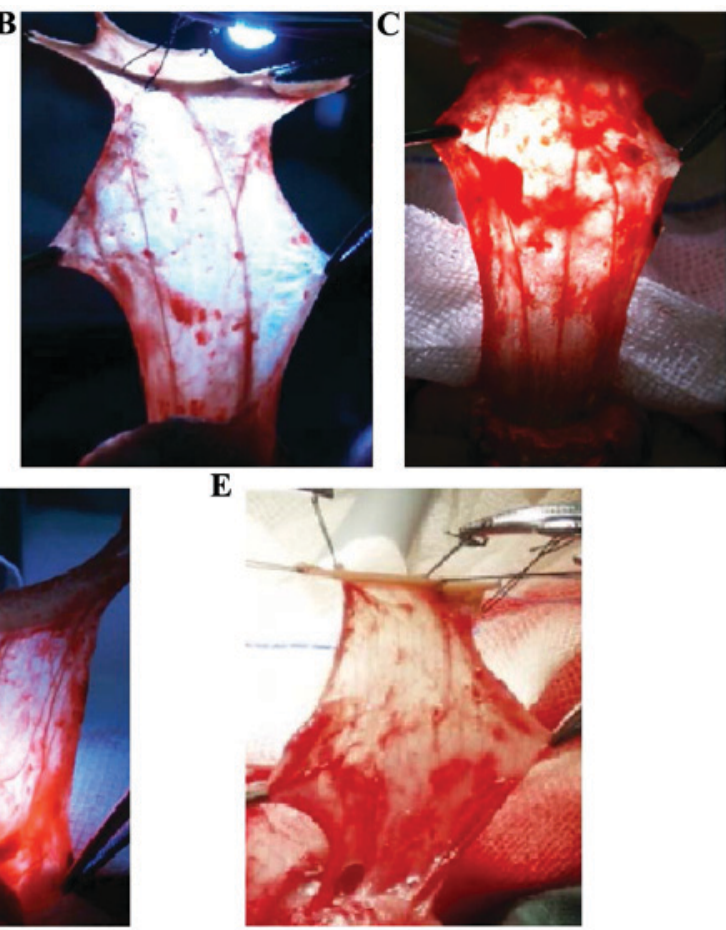

Figure 2. Vascular distribution type of vascular pedicle. (A) One blood vessel and (B) two blood vessels were predominant; (C and D) numerous blood vessels $(\mathrm{n} \geq 3$ ) were present; (E) no predominant blood vessel was present.

Table I. The vascular distribution type data for all groups according to their meatal location.

\begin{tabular}{lrrrrrr}
\hline $\begin{array}{l}\text { Vascular } \\
\text { distribution } \\
\text { type) }\end{array}$ & $\begin{array}{c}\text { Glanular } \\
\text { and } \\
\text { coronal }\end{array}$ & Penile & Penoscrotal Perineal & $\begin{array}{c}\text { Total } \\
(\%)\end{array}$ \\
\hline 1 & 10 & 20 & 18 & 1 & 49 & 42.6 \\
2 & 7 & 13 & 17 & 2 & 39 & 33.9 \\
Numerous & 4 & 5 & 6 & 4 & 19 & 16.5 \\
No predominant & 1 & 3 & 3 & 1 & 8 & 7 \\
vessels & 1 & & & & & \\
\hline
\end{tabular}

Chi-square test was carried out, $\mathrm{F}=\mathrm{P}=0.449>0.05$.

four were lost to follow-up. The follow-up findings showed: i) eight cases had urethral fistula and five cases had urethral stricture (Table II); and ii) the Chi-square test showed that the number of predominant vessels was not significantly related to urethral fistula $(\mathrm{P}=0.088)$ or stricture $(\mathrm{P}=0.866)$ (Table II).

\section{Discussion}

Surgery is the only curative treatment for hypospadias. The frequently used Duckett surgical method (7) is ideal for achieving a one-step repair of hypospadias accompanied by chordee of the penis. Duckett procedure has been performed with increasing success at Beijing Children's Hospital affiliated with the Capital Medical University for 30 years (8), and its most common short-term complications are urethral fistula, stricture, and diverticulum dilatation. The occurrence of urethral fistula and stricture may result from local tissue
Table II. The occurrence of urethral fistula and stricture by vascular distribution type in follow-up group.

\begin{tabular}{lccccc}
\hline $\begin{array}{l}\text { Vascular } \\
\text { distribution } \\
\text { pattern }\end{array}$ & $\begin{array}{c}\text { Total } \\
\text { no. of } \\
\text { follow-ups }\end{array}$ & $\begin{array}{c}\text { No. of } \\
\text { cases with } \\
\text { urethral } \\
\text { fistula }\end{array}$ & $\begin{array}{c}\text { No. of } \\
\text { cases with } \\
\text { urethral } \\
\text { stricture }\end{array}$ & $\begin{array}{c}\text { Urethral } \\
\text { fistula } \\
\text { rate (\%) }\end{array}$ & $\begin{array}{c}\text { Urethral } \\
\text { stricture } \\
\text { rate (\%) }\end{array}$ \\
\hline 1 & 36 & 2 & 3 & 5.6 & 8.3 \\
2 & 26 & 5 & 1 & 19.2 & 3.8 \\
Numerous & 14 & 0 & 1 & 0.0 & 7.1 \\
No predominant & & & & & \\
vessels & 3 & 1 & 0 & 33.3 & 0.0 \\
Total & 79 & 8 & 5 & 10.1 & 6.3 \\
\hline
\end{tabular}

Chi-square test was carried out among all four groups (urethral fistula: $\mathrm{F}=\mathrm{P}=0.088>0.05$, urethral stricture: $\mathrm{F}=\mathrm{P}=0.866>0.05$ ), and carried out between each two groups. All the P-values were $>0.05$.

ischemia and necrosis of the molding material used for urethra reconstruction. Moreover, preservation of blood supply to the island flap and remaining prepuce skin may be a key factor for improving the success rate of Duckett procedure and reducing the incidence of complications (9-11). Therefore, an accurate assessment of vascular distribution in the prepuce of children with hypospadias may create the foundation for improving the success rate of hypospadias treatment, and plays a critical role in preventing postoperative urethral fistula and stricture.

The distribution of vasculature in the normal prepuce is well-known. It is generally believed that blood vessels in the prepuce have two layers which can be easily separated. The junction of the inner and outer prepuce has the most abundant blood supply (12-15) and can serve as an island flap (7,9,16-19). 
This type of vascular distribution is the anatomic basis of Duckett procedure, as it not only ensures blood supply to the flap, but also prevents penis skin necrosis, which has been demonstrated once again in this study.

Although Duckett procedure has been used for $>30$ years since its initial description, and the flap design takes the vessel present in the foreskin into account. There has been no significant improvement in the success rate of the procedure. The lack of improved success is related to surgical skills, postoperative management by the operator, and the medical conditions of the operated children. However, some scholars argued that the blood supply to a prepuce affected by hypospadias varies greatly, and could be irregular. In other words, the actual factors that directly affect blood flow to the prepuce, and the degrees of variation in blood flow are not yet fully recognized and understood (20). Perovic and Radojicic (21) (2003) and Yucel et al (22) (2004) studied vascular distribution in hypospadias patients by using methods such as trans-illumination with a cold light source, microscopic observations after an injection of gelatin and Indian ink, methylene blue injection, and 3-D computer reconstruction after tissue sectioning. Both of those investigators identified four types of prepuce vascular distribution: i) one predominant blood vessel; ii) two predominant blood vessels; iii) two predominant blood vessels with ramus communicans (H-like form); and iv) no predominant blood vessel (net-like form). They also demonstrated the accuracy of data obtained by transillumination through the prepuce with a cold light source. While our current study used the same cold light method, the overall vascular distributions did not adhere to the rules reported by Perovic and Radojicic (21) and Yucel et al (22). Furthermore, we found that vascular distribution on the peduncle island skin flap was very regular. The distribution law pertaining to blood vessels found in the deep foreskin region as summarized in this study was similar to the general blood vessel distribution law described by Cağrı Savas et al (24). We suspect that the latter law reflects the former law. This is because prior to performing the transillumination test on foreskin with a cold light source, normal saline was injected into the foreskin to cause edema. This allowed superficial and deep vessels in the foreskin to be displayed in a clear hierarchy to be easily identified (Fig 1A). As Cağrı Savas et al (24) did not perform that step, direct transillumination with a cold light source did not help to distinguish between superficial and deep vessels. As a result, Cağrı Savas et al (24) observed the distribution of all superficial and deep vessels, and the deep vessels were thicker than the superficial vessels. When the foreskin was observed as a whole, deep vessel might have been mistakenly identified as main vessels.

Yucel et al (22) reported that the frequency of a net-like arterial system (no predominant blood vessel) was higher in more severe hypospadiac prepuces; however, this phenomenon was not observed in our current study (Table I). Moreover, we verified the simplicity and practicability of performing trans-illumination through the prepuce with a cold light source. It is possible to observe the vascular distribution and running of the prepuce in a clear and intuitive manner using this method. Perovic and Radojicic (21) reported that it is easier to create a peduncle island flap with a good blood supply in patients with a predominant vessel. While creating a peduncle island flap is not recommended for patients without an axial predominant vessel, such patients can still be treated with a stage operation. However, in our study, urethral fistula and stricture showed no association with the number of foreskin vascular pedicles, and there was no obvious difference in the incidences of urethral fistula and stricture between patients with and without vessels in the vessel pedicle. It is possible that blood supply to the neourethra is not only determined by the predominant blood vessel in the pedicle, but also by tissue surrounding the neourethra and remaining foreskin. Moreover, tissue surrounding the neourethra and the remaining foreskin might provide sufficient blood supply for the neourethra. Free grafts have been used to repair hypospadias for many years with a high success rate (23). Therefore, it is not always necessary to totally dissociate the vessel pedicle from foreskin tissue to retain all of the blood vessels in the vessel pedicle; instead, it is necessary to ensure that the vessels are not damaged. Trans-illumination with a cold light source can help surgeons to avoid vessel damage. Furthermore, the number of predominant vessels should not be the basis for determining whether to use a stage operation or a one-stage operation for hypospadias repair.

Cağrı Savas et al (24) reported that microvessel density was significantly decreased in hypospadiac children, and was negatively correlated with the severity of the condition. This finding suggests that blood supply to the neourethra or the occurrence of postoperation complications may be associated with microvessel density. Ceyhan et al (25) studied this possibility, and reported that reduced preputial microvessel density did not influence blood flow in cases of distal hypospadias. However, the relationship between blood flow and preputial microvessel density in other types of hypospadias (e.g., degrees III and IV) has not been investigated. Moreover, the association between microvessel density and surgical results (occurrence of complications) has not been reported, and requires further study.

In conclusion, the deep blood vessel distribution of prepuce in patient with hypospadias can be divided into four types. There is no exact congruent relationship between the type of vascularization and the meatal location. There are no significant differences in blood supply of prepuce among the different types. Vascularization of vessel pedicle has no exact relationship to urethral fistula or stricture. This study further demonstrates the anatomic basis of prepuce that Duckett surgery relies on. It is not necessary to dissociate the vessel pedicle from foreskin too much to keep all of the vessels in the vessel pedicle. Vascular integrity should be ensured and trans-illumination with a cold light source can help us to avoid vessel damage.

\section{Acknowledgements}

Not applicable.

\section{Funding}

This research did not receive any specific grant from funding agencies in the public, commercial, or not-for-profit sectors.

\section{Availability of data and materials}

The datasets used and/or analyzed during the current study are available from the corresponding author on reasonable request. 


\section{Authors' contributions}

ZZ collected the general data of patients. ZZ and NS performed the surgery. XM helped with statistical analysis. All authors have read and approved the final manuscript.

\section{Ethics approval and consent to participate}

Our study received approval of the Ethics Committee of Guangzhou Women and Children's Medical Center (Guangzhou, China), and informed consent was signed by the parents of the patients.

\section{Patient consent for publication}

Not applicable.

\section{Competing interests}

The authors declare that they have no competing interests.

\section{References}

1. Nelson CP, Park JM, Wan J, Bloom DA, Dunn RL and Wei JT: The increasing incidence of congenital penile anomalies in the United States. J Urol 174: 1573-1576, 2005.

2. Schnack TH, Poulsen G, Myrup C, Wohlfahrt J and Melbye M: Familial coaggregation of cryptorchidism and hypospadias. Epidemiology 21: 109-113, 2010.

3. van der Horst HJ and de Wall LL: Hypospadias, all there is to know. Eur J Pediatr 176: 435-441, 2017.

4. Westenfelder M: Treatment of hypospadias. Urologe A 31: 333-341, 1992 (In German).

5. Keays MA and Dave S: Current hypospadias management: Diagnosis, surgical management, and long-term patient-centred outcomes. Can Urol Assoc J 11 (Suppl 1): S48-S53, 2017.

6. Retik AB, Mandell J, Bauer SB and Atala A: Meatal based hypospadias repair with the use of a dorsal subcutaneous flap to prevent urethrocutaneous fistula. J Urol 152: 1229-1231, 1994.

7. Duckett JW Jr: Transverse preputial island flap technique for repair of severe hypospadias. Urol Clin North Am 7: 423-430, 1980.

8. Zhang N, Zhang W, Sun N, Bai J, Tian J, Li M, Song H and Huang C: Application of tubularized transverse preputial island flap urethroplasty for the repair of hypospadias. Zhonghua Xiaoerwaike Zazhi 31: 757-760, 2010 (In Chinese).

9. Duckett JW: Hypospadias. In: Campbell's Urology. Walsh PC, Gittes RF, Perlmutter AD and Stamey TA (eds). Vol 2. 5th edition. W.B. Saunders Co., Philadelphia, PA, pp1969-1999, 1986.
10. Retik AB and Borer JG: Hypospadias. In: Campbell's Urology. Walsh PC, Retik AB, Vaughan ED and Wein AJ (eds). 8th edition. W.B. Saunders Co., Philadelphia, PA, pp2284-2353, 2002.

11. Duckett JW Jr: The island flap technique for hypospadias repair. Urol Clin North Am 8: 503-511, 1981.

12. Juskiewenski S, Vaysse Ph, Moscovici J, Hammoudi S and Bouissou E: A study of the arterial blood supply to the penis. Anat Clin 4: 101-107, 1982.

13. Grossman JA, Caldamone A, Khouri R and Kenna DM: Cutaneous blood supply of the penis. Plast Reconstr Surg 83: 213-216, 1989.

14. Zhang F and Chen Z: Applied anatomy in urethroplasty by penile flap with external pudendal artery. J Pract Aesthetic Plast Surg 13: 236-237, 2002.

15. Chan IH and Wong KK: Common urological problems in children: Prepuce, phimosis, and buried penis. Hong Kong Med J22: 263-269, 2016.

16. Buckley J and McAninch J: Distal penile circular fasciocutaneous flap for complex anterior urethral strictures. BJU Int 100: 221-231, 2007.

17. Quartey JKM: Anatomy and blood supply of the urethra and penis. In: Urethral Reconstructive Surgery. Schreiter F and Jordan GH (eds). Springer, Berlin, Heidelberg, pp11-17, 2006.

18. Brandes SB (ed): Vascular anatomy of genital skin and the urethra: Implications for urethral reconstruction. In: Urethral Reconstructive Surgery. Current Clinical Urology, Humana Press, pp9-18, 2008.

19. Jiang XZ, Yang JF, Zeng Q, Wan B and He LY: Transverse preputial island flap technique (Duckett's procedure) forhypospadias repair: a report of 356 cases. Zhonghua Nan KeXue 17: 622-624, 2011 (In Chinese).

20. Mylchreest E, Cattley RC and Foster PM: Male reproductive tract malformations in rats following gestational and lactational exposure to Di(n-butyl) phthalate: An antiandrogenic mechanism? Toxicol Sci 43: 47-60, 1998.

21. Perovic SV and Radojicic ZI: Vascularization of the hypospadiac prepuce and its impact on hypospadias repair. J Urol 169: 1098-1101, 2003.

22. Yucel S, Guntekin E, Kukul E, Karaguzel G, Ciftcioglu A, Melikoglu M and Baykara M: Comparison of hypospadiac and normal preputial vascular anatomy. J Urol 172: 1973-1976, discussion 1976, 2004.

23. Hendren WH and Horton CE Jr: Experience with 1-stage repair of hypospadias and chordee using free graft of prepuce. J Urol 140: 1259-1264, 1988.

24. Cağrı Savaş M, Kapucuoğlu N, Gürsoy K and Başpınar S: The microvessel density of the hypospadiac prepuce in children. J Pediatr Urol 7: 162-165, 2011.

25. Ceyhan L, Cagri Savas M, Baspinar S, Duman L and Büyükyavuz BI: The correlation between preputial blood flow and microvessel density in distal hypospadias: A prospective clinical study. J Pediatr Urol 10: 103-106, 2014.

(i) $\ominus$ This work is licensed under a Creative Commons (c) ${ }_{\text {EY NO ND }}$ Attribution-NonCommercial-NoDerivatives 4.0 International (CC BY-NC-ND 4.0) License. 